\title{
Understanding of Power and Influence in an Indian Public Sector Organization
}

\author{
Subathra V
}

\begin{abstract}
This research aims to find out the understanding of power, how people acquire and exercise power in an Indian Public Sector Organization. The study also extends to understanding the strategic actions and tactics as a basis of which power is exhibited in organizations. A qualitative case study approach is followed to conduct this research and capture the lived-in experiences of the employees with respect to the research context. The data was collected through multiple interviews with employees working in all levels of the organization for a period of six months. The workplace communication patterns amongst the employees were also collected as empirical evidence to support the study. The study gives an understanding about the traditional power bases and dynamics in the organization. The findings explain that two of the traditional power bases, Legitimate and Expert power are still relevant and widely exercised in the organization. However, there was more emphasis on the existence of Knowledge and Connection Power in the organization. The study also indicates that there is a significant relationship between power influences and employee behaviour with respect to the attitude, relationships and communication patterns. The study paves way to eradicate the negative connotations associated with power in the society. The research is based on one organization. The data is subjected to respondents' bias and reluctance.
\end{abstract}

Index Terms- Employee Behaviour, Influence, Organizational Power, Power, Public Sector Organizations.

\section{INTRODUCTION}

Organizational Powercan be defined as "the ability to potentially influence employees, to overcome resistance, to change the course of actions and to get work done by individuals that they would otherwise not wish to do"[6]Ensuring that managers cannot be unconscious of the substances of their surroundings and cannot avoid from changing to deal those substances is the real trick in the organizational context.The use of power and influence is widely existent in organizations. The process of implementation of power and influence has its own problems. Wherein, the emphasis lies primarily on the method rather than the structure of organizational processes and systems. However, the objective is to view power and influence as one of the ways of getting things done in organizations, an important way but not the only way. Managing with power in organizations essentially implies understanding the fact that to get work done, power is required, more power than those whose resistance one should overcome which will consequently lead to the understanding of the sources of power and how these sources can be accessed and developed.

Ms. Subathra V, Department of Commerce, Kalindi College, University of Delhi, New Delhi, India.
It is of fundamental importance to employees to understand power and acquire it, failure of which will lead the employees to be less effective than they are expected to be. Managing with power also means understanding the strategic actions and tactics as a basis of which power is exhibited in organizations. Such an understanding will help the employees to become astute observers of the behavior of others.

Though there has been very little attention given to the concept of power in organizational theory and organizational learning, its considerations and its exercise are so central in the understanding of public organizations and other government bodies. The significance of power can be stated as an idea to understand the leadership skills and as a medium that enables the management to work profitably and effectively. The current study takes up one such organization to look at the power influences, dimensions and dynamics and an attempt to understand in depth the behaviour of employees subjected to power through their own experiences.

\section{STUDY CONTEXT}

In most democracies and in particular, India power has a very negative connotation to an extent where many individuals influence themselves they don't need anything to do with it. The moral fears associated with power are justifiable however, no one can abjure power. Power, as we are currently talking about it is essentially the ability to realize certain expected results in the behaviour of others. The word "Power" in almost all Public Sector Units is ubiquitous and fundamental in the understanding of how work is done and how employees ensure that the work is done effectively. To understand this one needs to understand the organization, the employee behaviour, how they possess power and what can be identified as the managerial implications of exerting the power they possess. The research findings and employee experiences are presented to examine the various power processes, decision making, influence, power tactics, resistance and effects of influence processes in organizations.

\section{LITERATURE REVIEW}

\section{A. Power}

The traditional and widely accepted definition of power in the organization context stated that the ability to get individuals to do what they would otherwise not do despite of their resistance is power[6]. The research conducted by Pfeffer gave an understanding between the relationship of the power holder and the individuals subjected to power. Power has a pervasive impact on the actions of the management and the responses of the employees with respect to those actions[1]. An issue which has been critical throughout is the actual definition of power. The study on"Who gets power and how 
they hold on to it: A strategic contingency model of power", indicated that the subunits in any organization that are able to adapt to the organization's uncertainties and critical issues tend to gain power[8]. Such critical incidents and uncertainties influence the decision making process in the organization. Adapting to the organization's environment is facilitated by the use of power.Power gained through information control is achieved mostly from the position in both informal and formal communication networks[6].

Power is the fundamental part of the management and is crucial to the relationship between the employees and their managers[11]. There has been a negative understanding of power as being very disruptive in relationships traditionally. The management must try to equalize power in the organization in order to facilitate improved communication and interaction[2]. The contemporary point of view is that power is both unavoidable and conceivably valuable. However, different conclusions may be derived about the dependence of the organizational actors and their directions[7].Power has been viewed as a converse of dependence[14]. Larger control and access to information and resources is available to those who possess central roles and network positions. They are in a position to control the relevant information and resources available to them which increase the dependency of others on them. Structure and behaviour have independent effects on power. Structure and behaviour effectively affect power. Structure may bring about power regardless of the involvement of behaviour strategies, or behavioural strategies might be related with power regardless of structure. By way of obtaining, maintaining and having complete control access to people, information and systems and processes the lower participants tend to achieve power. This enables the higher-ranking participants depend upon the lower participants.

Position power is derived from a person's position formally and gives the legitimate authority to exercise power and exert positive and negative endorsements such as rewards and coercion[13]. Thus, organizational hierarchy is a determinant of positional power which enables the ability to control the behaviour of others in the management and also to facilitate the processes and structure of the organization. Such use of power is direct and observable.Traditional studies have expanded the power bases beyond positional power which included not only legitimate power, reward power, and coercive power but also expert power and referent power. The concept of personal power for expertise, referent power, charisma, etc. was also widely used [13][15].

\section{B. Understanding Power}

Organizational Power revolves around 3 main issues:The Motive to acquire Power, The Bases of Power and the Consequences of having Power.The third area of research aims to examine how power influences those who possess it, and the managerial implications on the organization and the individuals subjected to power, which is the focus of the current study.

\section{Authority and the ability to influence}

Control or the ability to influence subordinates depends upon the subordinate's acceptance to such an aspect of the relationship. The inhabitants of the same or comparative positions inside an association contrast as to their capacity to impact their subordinates' exercises[2]. Authority is a role which is institutionalized or a system that enables power.
Authority is normally means the capacity which depends on the legitimate right given to an individual of specific higher position, to influence individuals to do things that they would not wish to do. Authority is away to influence with respect to the position the person holds this also gives the person certain rights to the ability to reward as well as punish[23].

\section{Influence}

Influence can be defined as the use of relevant resources which aims to change the behaviour of other individuals. Influence can be viewed as the essential outcome of power, it is characterized as the ability to change others' feelings, thoughts and behaviour[3][16]. Hence, when individuals possess power they tend to have an increased ability to influence others.

\section{E. Behaviour}

Research has shown that power impacts the behavioural aspects[17] which extends from the everyday activities such styles of dressing and eating habits, as to behaviour with significant noteworthiness, such as organizational decisions [18] intergroup stereotyping[19], and wrongdoing behaviour[20].A rundown of the behavioural approach through research has implied that that "power is exhibited through behavioural activities"[21].The structure of the organization provides access and control over the valued assets of the organization while practices to gain and deliberately utilize those assets become prevalent.The traditional bureaucratic structure of the organization interlocks and integrates the position and the respective behaviour[2]. The individuals who are a part of such a system perform certain duties and are answerable to certain people. The behaviours of the occupants of such positions are correlated previous to that particular occupancy.

\section{F. Sources of Power}

The two broad domains from where power can be generated include individual based characteristics and organizational structure based characteristics.

Individual Based Characteristics: Legitimate power, reward power, coercive power, expert power and referent power are the individual based characteristics. The characteristics are not mutually inclusive and independently exclusive as per the traditional method. These sources may be acquired separately or combined to achieve influence in organizations.

Structure Based Characteristics: Structure based characteristics are characteristics that generate power with respect to the structure of the organization. The structures include resource power, decision-making power, and information power. Each of these powers can be exhibited individually or combined in an organization to achieve influence.

\section{G. Factors Influencing Power}

- Expertise:Increase in specialization makes the employee an expert in the organization. Power is maintained because other employees become dependent upon the expert for the special skills and access to information

- Location and Position: The individual's area in location and position in physical and social space are imperative components impacting access to people, data, and resources

- Coalitions:The many channels of power and ways of achieving it forms an interesting part of the power processes within organizations. In complex 
organizations different functional groups possess its own power structure within the organization.

- Effort and Interest:The degree to which subordinates may practice power depends to some degree on their interest to apply exertion in regions where higher-positioned members of the organization are frequently hesitant to participate

- Attractiveness:Another individual trait related to power in an organization is the individual's personality or attractiveness. Individuals who are perceived to be as attractive more likely are to get access to people, information and in turn power

The gaps identified questions the relevance of the traditional bases of power in today's context. This paper addresses to study the relevance of the traditional bases of power in an Indian Public Sector Unit despite being identified as an hierarchical organization and its impact on employee behaviour.

\section{ORGANIZATION OVERVIEW}

The organization is a Public Sector Unit serving for over 50 years with around 8 branches all over the country. The Company has been registered under the Companies Act, 1956 and is being managed by its board of director and Managing Director (MD). The two people who have been authorized with delegated powers and responsibilities to manage and handle the day to day activities in the organization. They constitute the top-most management and meet in every quarter to discuss, consider and formulate the various policies. Every department of the organization consists of a Departmental Head, who is in charge to lay down the procedures of the company in alignment with the decisions and directives, the powers laid through the delegator positions, approved policies and other related rules which are applicable by law to facilitate the decision making. These procedures are formulated by the concerned officials to putting up to each superior officer for supervision / approval of the Competent Authority. The headquarters of the PSU where the research was conducted consists of around 223 permanent employees including helping staff and contract workers as on $30^{\text {th }}$ April, 2017.

\section{RESEARCH METHODOLOGY}

\section{A. Research Objective}

The main objective of the study was:

- To understand the sources of power acquired by employees in an organization

- To analyze the power dynamics prevalent in the organization

- To study the influences of power on employee behavior

The current paper focuses on the employee experiences while subjected to power and the impact it has on behavior, attitude and productivity of employees.

\section{B. Qualitative Approach}

The research objectives are extensive in the understanding of the sources of power and its impact on employees. The purpose of the study was to get insights on "how power play happens in the organization and how employees perceive and respond to it". A qualitative approach was adopted.According to [12] "because the context is intentionally a part of the research design in the case study method, there will dependably be too much 'variables' for the quantity of observations made."

"The existence of a particular phenomenon can abundantly be described by single case studies"[9]. The research was conducted through a Single Case Study Method where one organization was chosen to do a detailed study with a view to provide answers to the research question and give an insight to analyze the context of the study and the processes involved. The application of a standard tools and survey design is not applicable with respect to this study.

\section{Data Collection}

Data was collected from all levels and departments of the organization. The respondents were from top-level managers to ground staff. In-depth semi-structured interviews were conducted across levels in the organization. The workplace communication patterns amongst the employees were observed and noted. The observations of the interview process and the environment was observed and recorded by the researcher. The noted observations will be analyzed as part of the study. The employees were also encouraged to share interesting experiences where they have been prone to possess and exhibit power. The respondents were also further encouraged to share critical incidents where they have been subjected to power.

The interview schedule was constructed section-wise covering the following aspects in a sequential manner:

- Part 1: The association of the respondent with the organization

- Part 2: The respondent's understanding of power and the factors that influence power

- Part 3: The power dynamics of power in the organization which includes aspects such as power tactics, compliance, control and dependency

- Part 4: The influence of power on employees with respect to their behavior, attitude and communication patterns

- Part 5: The sources of personal power and its influence on the employees

- Part 6: The sources of socio-political power and its influence on the employees

- Part 7: The perception of the employees on the positive and negative impact of power play

The data collection was stopped because no new insights with respect to the concepts were generated. Sampling of more data did not lead to new information that would answer the research question i.e., theoretical saturation was achieved by clear evidence [10]

\section{Data Analysis}


Table 1: Recommendations by the Respondents

Power should be exercised only within the bounds of the designation or position;

Power should be used without harming other individuals;

Respondents' Suggestions

Power should be used for the larger benefit of the organization only;

Implementation of a reward system;

Training Needs for: Motivation, Leadership Skills, Personality \& Attitude, Communication Patterns and Conflict Management

A qualitative content analysis was adopted to analyze the data collected through the interviews. Categories discovered through the interview transcripts were developed according to grounded theory techniques* ("Glaser and Strauss 1967, 'theory building' through a combination of induction and deduction"). The categories were grouped to themes during analysis. The patterns and the emerging themes were identified and checked, with actual responses in the transcripts. The transcripts were analyzed independently from each interview and the themes and patterns were derived from the same. The key findings from the data collection process were developed by reviewing the themes that emerged. The themes included the major influences, trends and patterns that conceptualized the key factors of power influences in the organization. The researcher's observations was also analyzed and discussed as part of the methodology.

\section{FINDINGS}

As a part of the summative approach to qualitative content analysis, the data collected was analysed by calculating word frequency counts[5] for each dimension in the transcript. The findings are presented below with respect to the statements mentioned by the respondent in the course of the interview and the categories were grouped in accordance with the number of repetitions that occurred in the responses.

On analysing the transcript of every respondent, the data had certain recommendations that were given by the employees subjected to power. The recommendations revolved around aspects on what should be done by the top-management or the organization as a whole in order to facilitate effective management in terms of people and revenue management. The following are the findings with respect to the suggestions given in the data:

*Grounded theory is a research methodology that works inductively and involves the construction of theory through methodic gathering and analysis of data. 
Table 2: Research Findings

\begin{tabular}{|c|c|c|}
\hline Themes & Categories & $\begin{array}{l}\text { Responses } \\
\text { Frequency } \\
\text { Count }\end{array}$ \\
\hline $\begin{array}{l}\text { Understanding of } \\
\text { Power }\end{array}$ & $\begin{array}{l}\text { Authority } \\
\text { Power lies within everybody, Ability to get work done, Control } \\
\text { Ability to streamline things, Power is functional, Complete know-how, Strength, People who } \\
\text { pressurize other employees, Ownership over subordinates, Decision making ability }\end{array}$ & $\begin{array}{l}4 \\
2 \\
1\end{array}$ \\
\hline $\begin{array}{c}\text { Factors that } \\
\text { influence power }\end{array}$ & $\begin{array}{l}\text { Knowledge } \\
\text { Position } \\
\text { Pay Scale, Information on how to do things, Decision-making ability, Taking control } \\
\text { Roles \& Responsibilities } \\
\text { Skills, Attitude, Ability to do work, Relevance of the role, Credibility \& Performance, } \\
\text { Virtue, Ability to teach juniors, Experience/Seniority, Approach, Other Employees } \\
\text { Behaviour }\end{array}$ & $\begin{array}{l}6 \\
7 \\
2 \\
3\end{array}$ \\
\hline $\begin{array}{l}\text { Dynamics of Power: } \\
\text { Competition to } \\
\text { acquire power }\end{array}$ & $\begin{array}{l}\text { No competition exists } \\
\text { Yes } \\
\quad \text { - To sustain power, I have to } \\
\quad \text { - Power gives respect } \\
\text { Yes (but doesn't make any difference) }\end{array}$ & $\begin{array}{l}6 \\
5\end{array}$ \\
\hline $\begin{array}{l}\text { Do the powerful get } \\
\text { work done easily? }\end{array}$ & $\begin{array}{l}\text { NO (Work can be done only through care, affection, friendly behaviour, communication) } \\
\text { Yes (But with power and personality) }\end{array}$ & $\begin{array}{c}11 \\
4\end{array}$ \\
\hline Who is powerful? & $\begin{array}{l}\text { Senior Management } \\
\text { As per Seniority } \\
\text { Managing Director } \\
\text { People who are informative \& knowledgeable, Authoritative People, Unions, Bosses, AMs } \\
\text { (who face the customers), Depends on the roles \& responsibilities,People involved in the } \\
\text { decision making process } \\
\text { Everyone }\end{array}$ & $\begin{array}{l}8 \\
2 \\
7\end{array}$ \\
\hline $\begin{array}{c}\text { Power } \\
\text { Tactics/Power Play }\end{array}$ & $\begin{array}{l}\text { No power play takes places } \\
\text { Go well with bosses/Good relationships } \\
\text { Manipulative behaviour/Flattering } \\
\text { Influence your surroundings, Do favours and become influential, Make people obliged to do } \\
\text { work } \\
\text { Threats ("I will talk to the GM about this") } \\
\text { Favouritism, Preferences, Short term - be in the good books of the bosses, Gather } \\
\text { information, Spread rumours, Sympathy gainers/excuses, Conflicts }\end{array}$ & $\begin{array}{l}1 \\
1 \\
1\end{array}$ \\
\hline $\begin{array}{l}\text { Power Influence on } \\
\text { Employees }\end{array}$ & $\begin{array}{l}\text { Not much of an effect because of the time-scale promotion policy, Careless behaviour/ Don't } \\
\text { care attitude/Neglection of work } \\
\text { Gossips start, Conscious of the environment } \\
\text { Demotivation } \\
\text { It upsets others, Change in attitude and results, The relationship becomes weak, } \\
\text { Disheartened }\end{array}$ & $\begin{array}{l}1 \\
2 \\
3 \\
1\end{array}$ \\
\hline Personal Power & $\begin{array}{l}\text { Maintain good/healthy relationships } \\
\text { Make friends with employees } \\
\text { No pressure while working } \\
\text { Good connections, Personality/Popularity } \\
\text { Negotiating powers with suppliers } \\
\text { Leadership skills, Make people feel important,Managing/Administering, Staff relationship, } \\
\text { Attitude, Politeness, Behaviour }\end{array}$ & $\begin{array}{l}4 \\
7 \\
1 \\
3 \\
2 \\
1\end{array}$ \\
\hline $\begin{array}{l}\text { Socio-Political } \\
\text { Power }\end{array}$ & $\begin{array}{l}\text { NO } \\
\text { Gender disparities in leadership positions } \\
\text { Gender - the kind of interactions differ } \\
\text { Caste } \\
\text { Community/Region wise }\end{array}$ & 11 \\
\hline $\begin{array}{c}\text { Advantages of being } \\
\text { powerful }\end{array}$ & $\begin{array}{l}\text { Drives to work more, Larger benefit of the organization } \\
\text { Make people do what they have to do, Confidence \& Satisfaction, Otherwise no one will } \\
\text { listen to you, You get a grace and feel better, Positivity }\end{array}$ & 2 \\
\hline Disadvantages of & Responsibilities increases & 2 \\
\hline
\end{tabular}




\begin{tabular}{c|l|c}
\hline being powerful & Answerable, Accept challenges no matter what & \\
& No acknowledgement, People lose respect, Disliked by majority, Lose friends/relationships & \\
& Image will be degraded & 1 \\
& The corporation/organization suffers & 3 \\
\hline
\end{tabular}

respondent proceeded to the next question by giving incomplete answers. When there was a sense of another manager or employee nearing the interview space the eye contact was completely lost and the respondent seemed to be apprehensive and disturbed. There was also an instance wherein the employee standing next to the respondent was asked to support the answer with examples and critical incidents by exercising their power. Though the other person responded by supporting the answer of the respondent there was a sense of fear and unwillingness that was felt in the other person's responses. The respondents were highly reluctant in the beginning of the interview process wherein they refused to disclose their identity and quote examples to support their responses. One of the respondents even claimed that "how can we share incidents with you". Some of the respondents were very much contradictory in nature by way of their responses and the kind of expressions that they were wearing. For sections that covered questions with respect to power tactics, the respondents took a while to frame sentences and then respond.

\section{Emotional Context}

During the interview process, some respondents seemed to become furious while supporting their answers with examples of their own experiences. Respondents continuously repeated some statements to emphasize on what they were trying to convey. The respondents who perceived themselves to have been subjected to power or powerful managers felt a sense of submissiveness which was reflected in their responses. They clearly have mentioned that they possess no power in the organization and they tend to have a very negative understanding of power. However, people who perceived they have some kind of power in the organization felt a sense of ownership and command which was reflected in their responses.

\section{Resistance}

There has been a negative side of power relations and process of influence between individuals in the internal and external organizational environment which was reflected in the data. The statements that supported this analysis were "Power does not exists in our organization, your question is wrong", "there is nothing like power tactics in this organization, everything is good and everyone is friendly". However, unconsciously the respondents do accept that power exists in all organizational actions.

\section{TRIANGULATION \& DISCUSSION}

The data collected through the interview process and through the observations must be triangulated to form the basis for discussion. Triangulation[24]refers to the use of different data collection techniques within one study in order to ensure that the data are telling the researcher what she thinks they are telling. The studies in the diverse areas of psychology reveals that a broad range of behavioural aspects have been affected by power. The study objective was to 
understand the power bases in the organization and analyse its impact on employee behaviour. The following section would first summarize the power bases present in the organization. The section will then elucidate into the impact of power influences on the behaviour of employees as indicated by the respondents.

\section{A. Understanding of Power}

The respondents seemed to have a negative understanding of power. The category that emerged to be the most prominent among the responses was the understanding of power closely associated with authority, the ability to instruct, the ability to command, the ability to control the subordinates with respect to the power holder's position and designation. One of the respondents categorically stated that "Power is the demand of the designation you are in". The employees in the organization understand power as the asset that employees own with respect to their position and key deliverables in the organization.However, another category that was prominent was the understanding of power as a strength that lies within oneself. The employees do understand that each one of them possess some kind of power or another closely in alignment with their roles and responsibilities in the organization.

\section{B. Power Bases}

\section{Position Power}

From the data collected through interviews, the most prominent power bases that was present in the organization as perceived by the employees was the power bases of position. The formal, legitimate authority possessed by an employee with respect to his/her position was the most common response that was received. Other categories that also submerged within position were responses such as top management, senior officials, the General Managers, Managers and the Managing Director and their respective roles and responsibilities. The power acquired with respect to the position was also closely cited as the decision making ability or the power to make decisions which broadly involved the four stages such as initiating, providing information, choosing the course of action, and implementing action as indicated by the respondents through examples and encounters with the top-management officials.

\section{Knowledge and Information Power}

The next power base that was equally prevalent in the organization was the power of information and knowledge. People who were perceived to possess information about the products, the systems, the people and the processes seemed to be the most powerful. The employees who were experienced and who were the senior most with respect to age in the organization were perceived to be powerful. Statements claim that people who are experiences, informative and knowledgeable tend to be powerful.

\section{Power Dependency}

People who possess immense knowledge and expertise over certain skills also tend to acquire power. An example given by one of the respondents claiming that the assistant working in the IT services department is the most powerful in the organization because he is the only person whose name is taken by everyone in the organization when IT related issues arise. Individuals, who have the knowledge and expertise over a particular skill, tend to create a dependency factor in the organization.

The dependency created gives power to the person to whom other employees are dependent on. If an individual A is dependent on another individual $\mathrm{B}$; $\mathrm{B}$ has a power that creates this dependency.

Knowledge without the power to exhibit is remarkably of no use. Similarly, power without the right kind of knowledge to employ it efficiently likely gets to be wasted. Thus, knowledge and information sharing constitutes an important part in understanding the power bases in the organization. It can also be deducted that the aspects of power does not only flow from the norms and rules set by the organization but also by the characteristics and behaviors of the individuals.

\section{Personal/Connection Power}

In addition to the knowledge and position power present in the organization, the organization also has a prominent personal power. Power with respect to the personality of employees, their attitudes, the kind of relationships they tend to have with other employees, the ability to create connections with people and maintain friendly relationships to get work done was constantly mentioned by majority of the respondents. Statements like "If I help him today, he will be obligated to help me tomorrow"justifies this claim.

\section{Power Tactics}

Every employee in an organization has independent goals. With the perception that power is limited in a public sector organization, managers and subordinates tend to get competitive to achieve independent roles. Employees who are subjected to power explain incidents wherein how other employees compete by using behavioral tactics in the organization. Illustrations like "People in this organization want to build them up by tearing others down" which indicate the perceived negative bias in the employees.

One of the respondents claimed that "Power gives you respect". The possession of power was expected to give space and respect to the power holder which propels employees to compete in order to acquire power. The respondents also claimed that there is an ease of working in the top-management because of the presence of subordinates from whom work can be get done. A reason why power play happens in an organization is to sustain one's position with respect to the reputation and image he/she carries. Employees are in a position to acquire some kind of place for themselves as a means to shine in the organization.

"People with high power have been shown to pay less attention to others and to use stereotypes more"[22]. Managers also tend to believe that if their subordinate over-performs their power gets diminished and effectiveness reduces. For the reason which the manager fails to give acknowledgments and appreciation to his/her subordinates. Power in this organization is primarily used to influence organizational decisions under circumstances that both require and favour its use.

The other behavioural aspects such as maintaining good relationships with immediate bosses, flattering, doing personal work, doing favours for other employees and making them obliged to do work for oneself and gossiping are other power tactics played by the employees in this 
organization.

\section{Impact on Employee Behaviour}

From the data collected from the interview process, it was observed that there is no impact on the employees with respect to acquiring a particular designation because the organization practises a time-scale promotion policy. However, in relation with the behaviour of the employees in the workplace the respondents mentioned the impact of being subjected to power and its respective changes. One of the respondents mentioned that the behaviour of the employee changes when the individuals who are claimed to be the most powerful in the organization are around. Statements like "when Sir comes, you are entitled to give respect" justifies the changes in the actions of the employees. However, when the higher authority is around and monitoring the work of the subordinates, it exhibits a sense of conscious behaviour and a feeling that the manager does not trust the subordinates. The categories that emerged emphasized that the employees lose motivation and exhibit a careless behaviour when they are subjected to power. The respondents mentioned the communication patterns of the individuals who are power holders such as "If asked politely, we can cooperate" supports the claim that communication patterns impact employee behaviour both positively and negatively.

The responses reflected on the sensitive side of the employees' feeling wherein it was indicated that with the exertion of power by the power holders the relationship between the power holder and the individual subjected to power weakens and gradually declines. Most of the respondents mentioned that the relationship will be brokenor weakened and they tend to lose their friends. The way power has been exercised sometimes upsets other employees. The manager's authoritative behaviour of getting work done will have positive and negative impact on the employees. Statements like "It is his job requirements to command and instruct" it is justified that some employees feel compliance and commitment whereas some employees feel resistance and reluctance.

On analysing the positive factors of the power holders, they tend to gain confidence and optimism in the workplace and can get work done by exhibiting the power. As quoted by a respondent, "I am all in all in the department" signifies the extent to which the power possessed by the individual creates a feel good factor in them. However, it was also indicated that power tends to over load people with many responsibilities and creates a situation wherein they enter a state to be answerable to the higher authorities.

In this organization, it has been analyzed and observed that both the functional and dysfunctional attributes of organizational political climate is present. Individuals do possess power of expertise and also claim to exaggerate the work delivered. As highlighted earlier, information power is an important power base in the organization where information is not only accessed formally but also can be accessed informally. This is one of the real ways to get work done, by accessing information.

Finally, 'connection power', the fourth power base, is related to the notion of networking and relationship building. It can be obtained through external, central and internal networks. This is one of the most emphasized power bases in the organization. Connecting the facts with respect to the organization, it was mentioned earlier that "People will help me only if I maintain friendly and cordial relationships". Individuals do favors for each other so that the one who has been favored feels obliged to help the individual in future. In this organization, there is a huge amount of negotiation power that every employee has with their suppliers/clients. Such situations compel the employee to network effectively and sustain connections with the customers, the supplier and the organization itself. On the other hand, individuals could build networks with the suppliers to buy products for themselves too at lower margins. The importance of making connections and maintaining relationships was strongly felt through the case of this organization which also reflects the strong Indian Culture induced in the public sector unit. The importance of creating a family oriented culture even in the workplace, to take people along and emphasize on faith, trust, care, affection and loyalty is strongly felt through the data collected from the interview process.

In summary, the four power bases provide a comprehensive account on how analyzing the functional and dysfunctional political climate of the organization.

\section{MANAGERIAL IMPLICATIONS}

Managers and employees depend on each other and the behaviour of either of them is determined mutually. The identification and acquisition of power bases provide a framework that HR practitioners can use to inform their strategies for organizational effectiveness. However, employee involvement in the effective use of power is crucial in every organization. This also emphasizes on the fact that the belief system of the employees about the negative connotations of power must be eradicated. The managers who view power as a growth opportunity are motivated and able to exercise their assistance and support to employees and develop friendly relationships while simultaneously feeling their own power reinforced. Employees in a public sector context have the tendency to feel dissatisfied and alienated if there is an indisputable gap between exercisingpower and employee feelings. This lack of alignment needs to be addressed to ensure optimum efficiency and productivity.

\section{RECOMMENDATIONS}

In a summary, it is recommended to the management that the initiatives to educate and orient the employees about the power bases existing in the organization in such a way that the positive connotation of power is felt amongst the employees. Further the human resources practitioners or the personnel department of the organization must take organizational initiatives with an aim to empower the employees and make them aware of how to identify, construct and utilize the range of power bases available to them. An implementation of systems, procedures and workshops to support the functional political climate of the organization will be a positive action. Since power is not a unitary concept and it involves the power holder perspective as well as the perspective of the individuals subjected to power, it is of extreme importance to emphasize that the shared values, 
goals and vision of the organization allows the possibility that multiple groups exercise power at the same time without harming or upsetting any particular individual. Power is exercised on different levels by different employees at different times however, power on a functional level is important to align the behavior of the employees with the strategic decisions of the management. The management rather than minimizing or avoiding power should get oriented and adapted towards providing help to each other to grow and develop the valued resources in the organization. The organizational political climate that was exhibited through the analysis of the data should be recognized as an organizational reality. Managers should seek to develop "power-with" the employees rather than "power-over" them. Training workshops on emphasizing the leadership skills, personality and attitude, communication processes and conflict management will enable the management to perform effectively.

\section{CONCLUSION}

The paper has reported a study of a Public Sector Unit, where power dynamics and influences of power play on employees have been analysed. The study hasfound that the sources of the power bases in the organization are based on the individual characteristics rather than structural based characteristics. The most prominent power bases prevalent in the organization have been found to be position power and expertise power which are traditional sources of power. Despite being identified as an hierarchical organization existing in the Indian governmental set-up, it is found that knowledge power and connection power are widely existent among the employees in the organization irrespective of differences in the position they hold in the organization.Position and expert power have been prominent in most research work and has been adapted as the traditional bases of power, the presence of information/knowledge power and connection power have been discovered as the trending bases of power in this organization.

The current case also indicates the importance of establishing connect with managers, subordinates, suppliers and customers. The organization seems to possess core values of unity and family oriented culture aligning with the Indian cultural values and systems. There was a drastic trend in emphasizing on maintaining friendly relationships with employees to get work done. Further, the impact of these tactics may be seen as being reflected in the individual in most of the behavioral parameters. The exercise of power through authority seems to have a negative impact on employee behavior. The case had potentially important implications for the study and practice of leadership in organizations.To summarize, the study concludes that knowledge-information, assistance, emotional support and the ability to solve problems form the bases of power in the organization emphasizing the need to exchange resources and expertise, discuss conflicts and integrate different views in a broader perspective for the larger interest of the organization.

\section{ACKNOWLEDGMENT}

The author would like to extend gratitude and acknowledge the constant support, mentoring and guidance provided by Dr. Richa Awasthy, Associate Professor, Organizational Behavior Area, School of Business, Public Policy and Social Entrepreneurship, Dr. B.R. Ambedkar University Delhi in writing and complete this research paper.

\section{REFERENCES}

[1] Anderson, C., \& Berdahl, J. L. (2002). The experience of power: Examining the effects of power on approach and inhibition tendencies. Journal of personality and social psychology, 83(6), 1362.

[2] Bennis, W. G., Berkowitz, N., Affinito, M., \& Malone, M. (1958). Authority, power, and the ability to influence. Human Relations, 11(2), 143-155.

[3]Comstock, D. E. (1980). Dimensions of influence in organizations. Pacific Sociological Review, 23(1), 67-84.

[4] Gold, R. L. (1958). Roles in sociological field observations. Social Forces, 36(3), 217-223. doi: 10.2307/2573808

[5] Kondracki, N. L., Wellman, N. S., \& Amundson, D. R. (2002). Content analysis: Review of methods and their applications in nutrition education. Journal of nutrition education and behavior, 34(4), 224-230.

[6] Pfeffer, J. (1992). Understanding power in organizations. California management review, 34(2), 29.

[7] Posner, B. Z., \& Kouzes, J. M. (1988). Relating leadership and credibility. Psychological reports, 63(2), 527-530.

[8] Salancik, G. R., \& Pfeffer, J. (1977). Who gets power-and how they hold on to it: A strategic-contingency model of power. Organizational dynamics, 5(3), 3-21.

[9] Siggelkow, N. (2007). Persuasion with case studies. The Academy of Management Journal, 50(1), 20-24.

[10] Strauss, A. \& Corbin, J. 1998. Basics of Qualitative Research. Thousand Oaks, CA: Sage Publications.

[11] Tjosvold, D., Andrews, I. R., \& Struthers, J. T. (1991). Power and interdependence in work groups: Views of managers and employees. Group \& Organization Studies, 16(3), 285-299.

[12] Yin, R. K. (1981;2003). Case study research: Design and methods. Thousand Oaks, CA: Sage.

[13] Bass, B. M. (1960). Leadership, psychology, and organizational behavior.

[14] Emerson, R. M. (1962). Power-dependence relations. American sociological review, 31-41.

[15] Elias, S. (2008). Fifty years of influence in the workplace: The evolution of the French and Raven power taxonomy. Journal of Management History. [16] Cialdini, R. B., \& Goldstein, N. J. (2004). Social influence: Compliance and conformity. Annu. Rev. Psychol., 55, 591-621.

[17] Krekel, C., Ward, G., \& De Neve, J. E. (2019). Employee wellbeing, productivity, and firm performance. Saïd Business School WP, 4.

[18] Gruenfeld, D. H., Mannix, E. A., Williams, K. Y., \& Neale, M. A. (1996). Group composition and decision making: How member familiarity and information distribution affect process and performance. Organizational behavior and human decision processes, 67(1), 1-15.

[19] Fiske, S. T. (1993). Controlling other people: The impact of power on stereotyping. American psychologist, 48(6), 621.

[20] Green, D. P., Strolovitch, D. Z., \& Wong, J. S. (1998). Defended neighborhoods, integration, and racially motivated crime. American journal of sociology, 104(2), 372-403.

[21] Thompson, K. R., \& Luthans, F. (1983). A behavioral interpretation of power. Organizational influence processes, 72, 86.

[22] Operario, D., \& Fiske, S. T. (2001). Effects of trait dominance on powerholders' judgments of subordinates. Social Cognition, 19(2), 161-180.

[23]Weiss, R. M. (1983). Weber on bureaucracy: management consultant or political theorist?. Academy of management review, 8(2), 242-248.

[24]Denzin, N. K. (2012). Triangulation 2.0. Journal of mixed methods research, 6(2), 80-88.

Ms. Subathra V, is currently working as an Assistant Professor in the Department of Commerce, Kalindi College, University of Delhi. She is pursuing her Ph.D in Management from the faculty of Management Studies, University of Delhi. She is a Management Graduate from the School of Business, Public Policy and Social Entrepreneurship.Her research work lies majorly in the area of Human Resources Management, Education and Business Management. 